\title{
Classification of Zagros earthquakes based on focal mechanism
}

\author{
Mehdi Nouri DELOUEI ${ }^{1}$ (D), Mohammad-Reza GHEITANCHI ${ }^{2, *}$ (D) \\ ${ }^{1}$ Department of Geophysics, North Tehran Branch, Islamic Azad University, Iran; \\ e-mail: mndmha@gmail.com \\ ${ }^{2}$ Institute of Geophysics, Tehran University, Iran; e-mail: mrghchee@ut.ac.ir
}

\begin{abstract}
The Zagros suture zone is seismically active region in Iranian plateau. This region is of high importance in terms of seismicity, since it is a vast and populated region and in recent years the earthquakes with high intensities have frequently occurred and have caused extensive destruction and heavy human loss. The study of the focal mechanism is very important in understanding the seismotectonic characteristics. Focal mechanisms of Zagros were collected over a period of 20 years and they were classified by FMC software. Seven groups were considered for the type of faulting and Zagros was divided into three zones. For each zone, the frequency percentage of each group of faults was determined. The most of faulting are of the reverse and compression type with the strike-slip component. Finally, the role of nodal plane selection in determining the type of faulting was discussed and it was found that the selection of each nodal plane in determining the type of faulting has the same result.
\end{abstract}

Key words: classification, FMC software, focal mechanism, nodal plane, Zagros

\section{Introduction}

The Zagros suture zone is seismically active region in Iranian plateau. More than 50 percent of the earthquakes reported by the national seismic network have occurred in Zagros (Mirzaei et al., 1998). This region is of high importance in terms of seismicity, since it is a vast and populated region and in recent years the earthquakes with high intensities have frequently occurred and have caused extensive destruction and heavy human loss. The $2017 \mathrm{Ms}=7.3$ earthquake of Sarpol-e-Zohab is one of the most important events of Zagros in recent years. According to the report of the International Seismological Research Institute (IIEES), the fault which caused this earthquake was one of the plates with north-northwest direction of the fault of the mountain which has a slope with a very low angle (10-15 degrees) to the eastward.

\footnotetext{
*corresponding author: e-mail: mrghchee@ut.ac.ir
} 
In this paper, the focal mechanisms of Zagros earthquakes are classified using FMC software developed by Álvarez-Gómez (2018). FMC was originally developed on Python 2.7.3 and adapts some of the Gasperini and Vannucci (2003) FORTRAN routines to obtain the different parameters of the earthquake focal mechanisms. The default input and output formats are the same used by the GMT program "psmeca" in order to make the program integration easiest and facilitate the mapping of the data (ÁlvarezGómez, 2018). First, the whole area of Zagros was selected and then, due to the large area of Zagros, it was divided into three parts and focal mechanism classification was done for all three parts. Finally, the importance of selecting nodal planes in determining the type of fault was discussed.

\section{Tectonic setting}

The Zagros area can be divided into two main parts: High Zagros and Folded Zagros. The High Zagros extends from the northwest to the southeast as a high wall but with rather low width (at most $80 \mathrm{~km}$ ). The highest mountains of Zagros including Dena, Zardkooh, Eshtrankooh and Green, are located in the High Zagros. The western and the southern part of Zagros Mountains, $1370 \mathrm{~km}$ in length and 120 to $250 \mathrm{~km}$ in width is called the folded Zagros. This part of Zagros parallel to High Zagros extends to the Persian Gulf and the Strait of Hormuz. Large and extended anticlines are characteristics of the folded Zagros. The most important faults of the Zagros zone are (Fig. 1):

a) The High Zagros Fault (HZF): the HZF is a large thrust fault in the Zagros Mountains which is considered as the southern border of High Zagros and separates this area from the Folded Zagros.

b) The Zagros Main Front Fault (MFF): The MFF forms the southern border of the Folded Zagros. This blind and piece by piece thrust has special characteristics of structure, topography, geomorphology and seismotectonics. The MFF is a combination of discontinuous driven pieces with 15 to $115 \mathrm{~km}$ in lengths which is totally $1350 \mathrm{~km}$ long in Iran.

c) The Main Zagnros Reverse Fault (MZRF): The MZRF is essentially a collection of several smaller faults along each other which considered as the northern border of the High Zagros. This reverse fault has a 
low-slope thrust-compression mechanism and plays a significant role in the seismicity of Iran and the Zagros.

d) The Main Recent Fault (MRF): The MRF is a narrow zone and a collection of several sections of right-lateral strike-slip fault, which is mostly parallel but completely different from the MZRF and intersects it in several places. These faults, together with the MZRF, form the north-eastern boundary of the Zagros folded and thrust belt. The total length of this fault is about $800 \mathrm{~km}$.

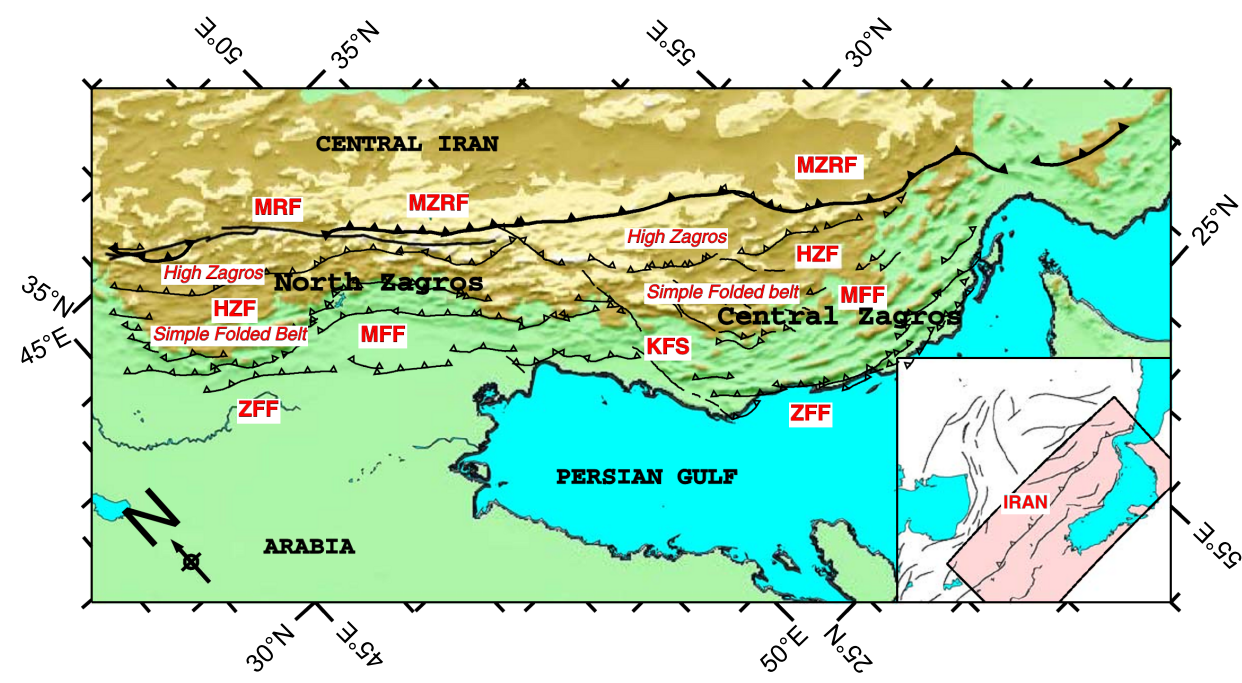

Fig. 1. The main geographical and tectonic features of the Zagros (Hatzfeld et al., 2010). The four faults explained in this paper: MZRF - Main Zagros Reverse Fault; MRF Main Recent Fault; HZF - High Zagros Fault; MFF - Main Front Fault.

\section{Data}

About 251 focal mechanisms were collected from CMT catalogue (The Global Centroid-Moment-Tensor Project at https://www.globalcmt.org/, Dziewonski et al.,1981; Ekström et al., 2012), their distribution is shown in Fig. 2. According to the distribution data, the Zagros was divided into three zones. Thus, we can compare the different zones of Zagros in addition to the general investigation of the classification of focal mechanism in Zagros. In these zones, 45, 65 and 141 focal mechanisms (for zones 1, 2 and 3, respectively) were available. It is worth mentioning that the general trend 
of seismicity in Zagros is in the way that with its movement from West to East the frequency of the events increases.

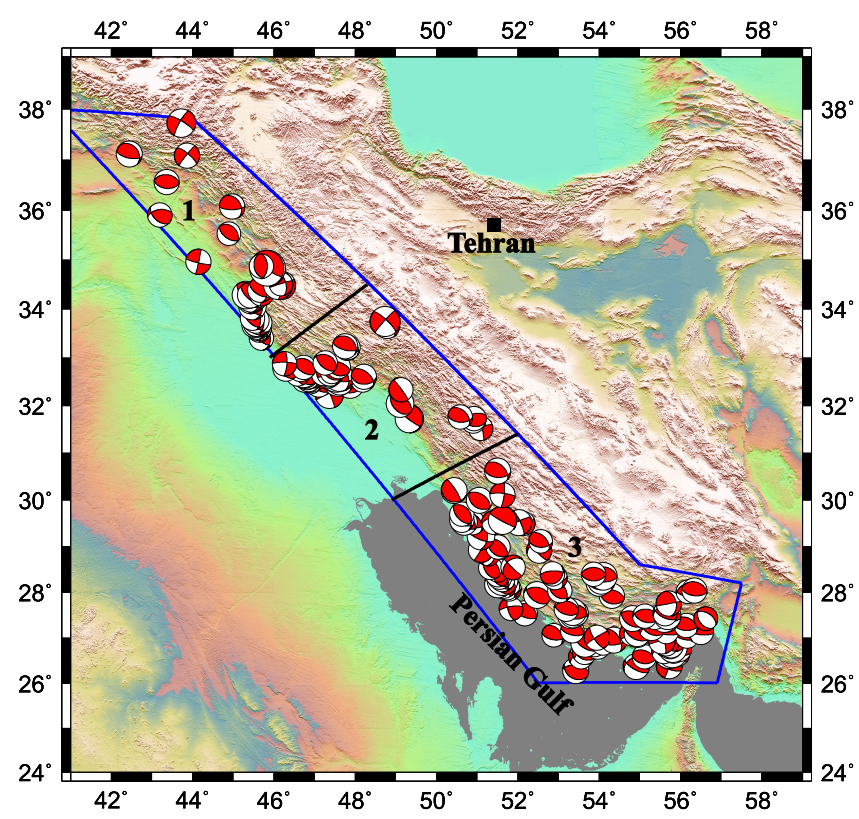

Fig. 2. Distribution of Zagros focal mechanisms with limited area of three zones.

\section{Classification}

In this paper, the tectonic characteristics of Zagros have been studied using the focal mechanisms obtained from the earthquakes of the region in a period of 20 years (from 2000 to 2020). First the focal mechanisms were collected from CMT catalogue. The range of magnitudes of the earthquakes spans from 4.5 to 7.3 in moment magnitude scale. Most earthquakes are shallow, about $70 \%$ of them have $30 \mathrm{~km}$ depth.

In this study, we classify these focal mechanisms so that the type of faulting (reverse, strike-slip and normal) can be determined according to their frequency distribution. We have used the software FMC which has been written in Python. In this software the focal mechanisms are divided into seven groups: Normal (N), Reverse (R), Strike-slip (SS), Strikeslip-Reverse (SS-R), Strike-slip-Normal (SS-N), Reverse-Strike-slip (R-SS), 
Normal-Strike-slip (N-SS). The diagrams of these classifications have been shown in Kaverina et al. (1996) projection technique (Fig. 3). This diagram also is used by Kagan (2005).

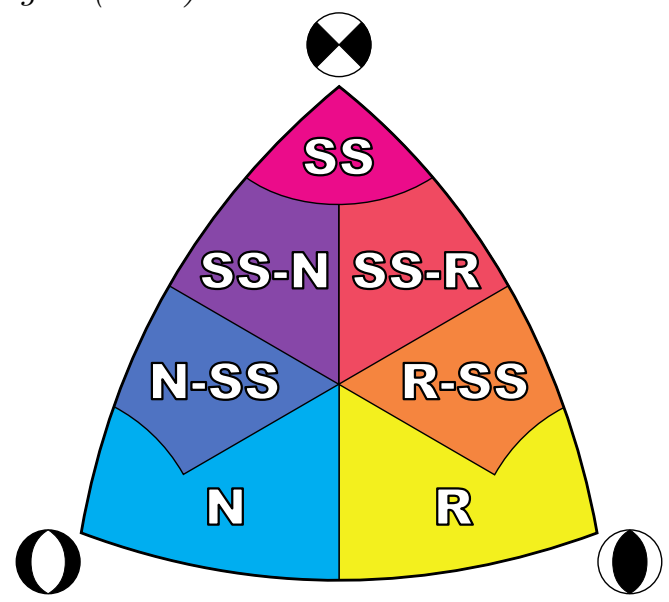

Fig. 3. Seven groups of focal mechanism in the classification diagram (Álvarez-Gómez, 2018). N: Normal; N-SS: Normal-Strike-slip; SS-N: Strike-slip-Normal; SS: Strike-slip; SS-R: Strike-slip-Reverse; R-SS: Reverse-Strike-slip; R: Reverse.

According to the analysis of the eigenvalues and eigenvector, every moment tensor has three eigenvalues (the maximum value $\mathrm{T}$, the middle value $\mathrm{B}$, the maximum value $\mathrm{P}$ ) whose direction are determined by eigenvectors. The direction of these three vectors determines what type of faulting is shown by a focal mechanism and to which category of the seven above mentioned groups should belong to. The Figure 4 flowchart shows the classification based on the direction of the vectors of $\mathrm{P}, \mathrm{B}$ and $\mathrm{T}$.

\section{The results of classification}

First in this section the classification of the focal mechanisms for the whole Zagros has been shown (Fig. 5), then for the zones 1, 2 and 3 (Fig. 6). As it is shown in Fig. 5, most faulting is of reverse and strike-slip type. A smaller number of the normal type is observed. The results of the zones 1,2 and 3 have been shown in Fig. 6. The common feature among all is the high frequency of the reverse category and then the strike-slip category. It is interesting to notice that there is no registered focal mechanism in the nor- 


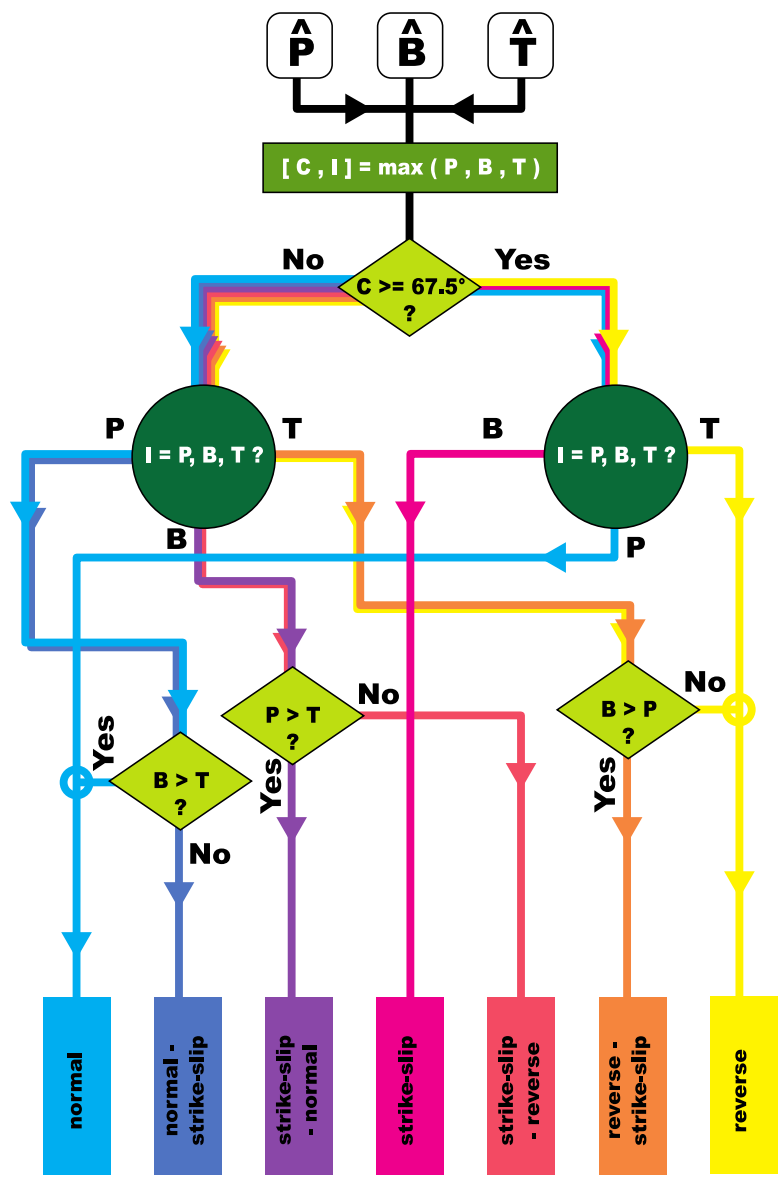

Fig. 4. The focal mechanism classification flowchart.

mal category of classification in zone 2. A pie chart of percentage frequency of these seven categories has been shown in order to better understand the classification (Fig. 7).

\section{Comparison of classification with eigenvector and classifi- cation with rake}

In addition to eigenvector of moment tensor, we can use rake direction to find out the type of faulting (Fig. 8). On other hand, we have two planes 
perpendicular to each other to solve the focal mechanism. Here, first we make a comparison for the diagnosis of faulting using the rake of these two planes, subsequently we compare each one of them with the analysis of eigenvector as well. The method of the fault type diagnosis is shown in Fig. 8. The rake varies from $-180^{\circ}$ to $180^{\circ}$. The rake values of 0 and 180 degrees indicate the faulting of pure strike-slip, 90 degrees indicates reverse and -90 degrees indicates pure normal faulting. The other amounts indicate the intermediate faulting and the combined faulting. The Heatmap
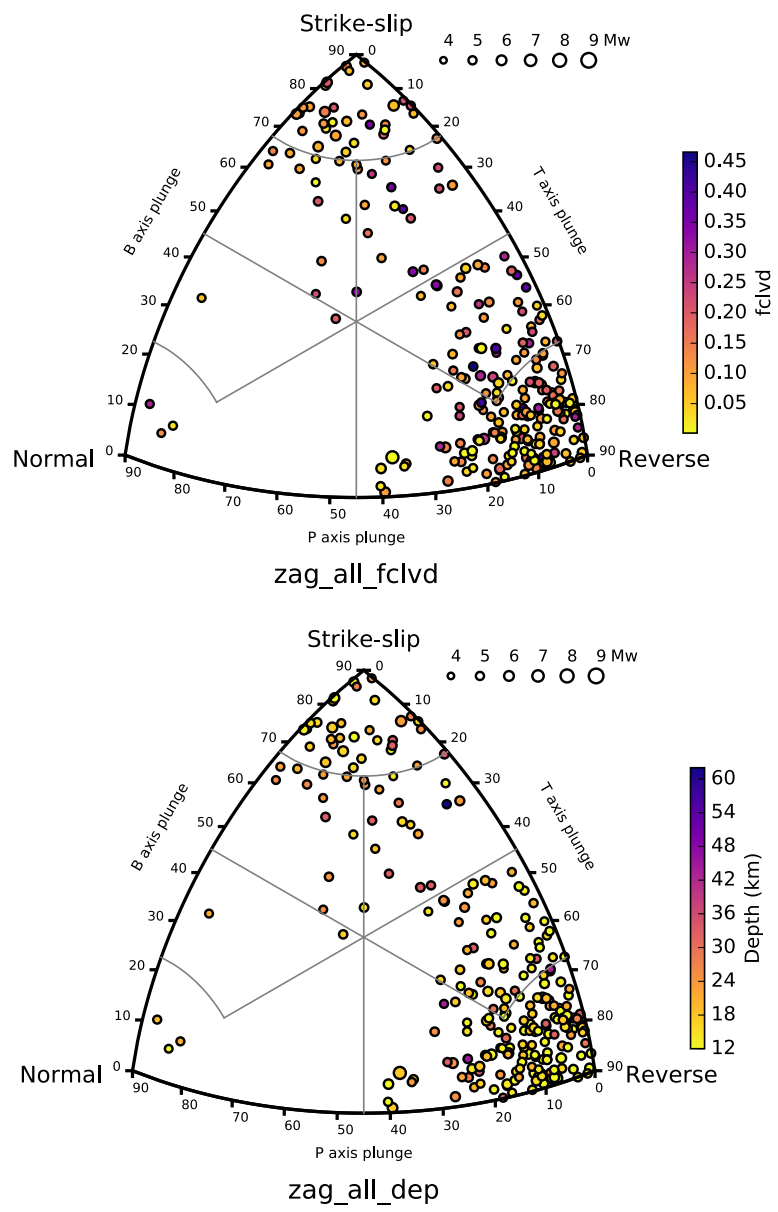

Fig. 5. Classification of the Zagros focal mechanism in fclvd scale (top) and depth scale (bottom). 

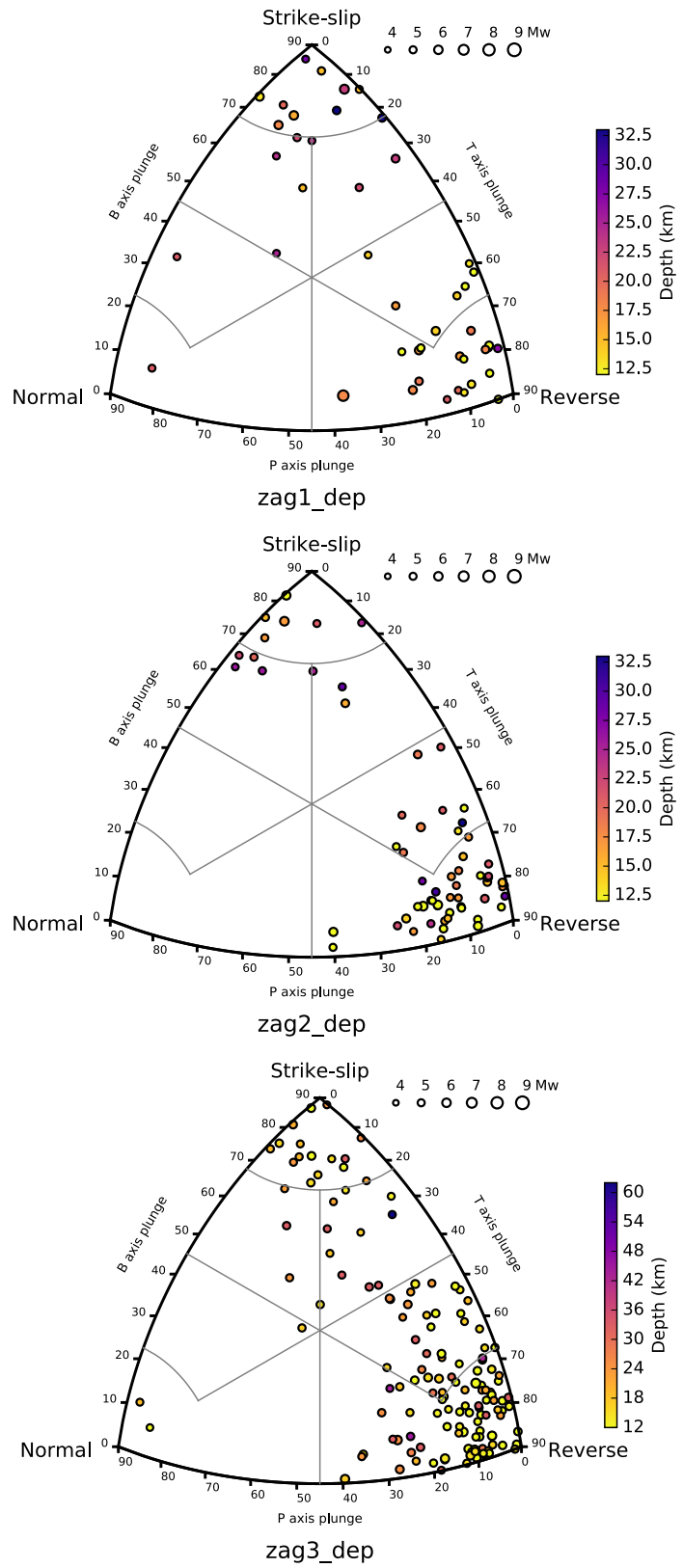

Fig. 6. Classification of the Zagros focal mechanism in depth scale for zone 1 (top), zone 2 (middle) and zone 3 (bottom). 


\section{Zagros}

SS $\square$ SS-N $\square$ SS-R $\square \mathrm{N} \square \mathrm{N}-\mathrm{SS} \square \mathrm{R} \square \mathrm{R}-\mathrm{SS}$

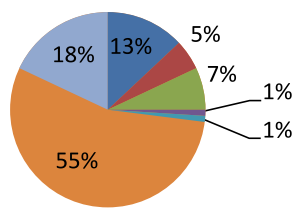

\section{Zone 2}

SS $\square$ SS-N $\square$ SS-R $\square \mathrm{N} \backsim \mathrm{N}-\mathrm{SS} \square \mathrm{R} \backsim \mathrm{R}-\mathrm{SS}$

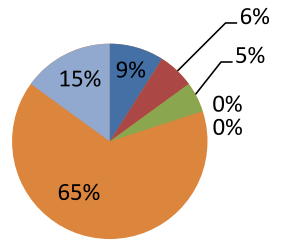

Zone 1

SS $\square$ SS-N $\square$ SS-R $\square \mathrm{N} \square \mathrm{N}-\mathrm{SS} \square \mathrm{R} \square \mathrm{R}-\mathrm{SS}$

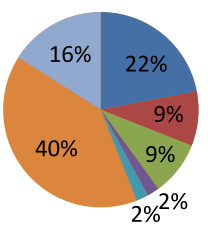

\section{Zone 3}

SS $\square S S-N \backsim S S-R \square N \backsim N-S S \square R \backsim R-S S$

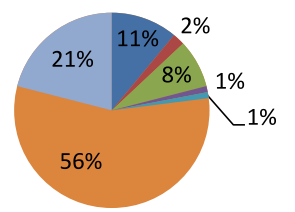

Fig. 7. Pie charts of frequency percentage for Zagros and its 3 zones.

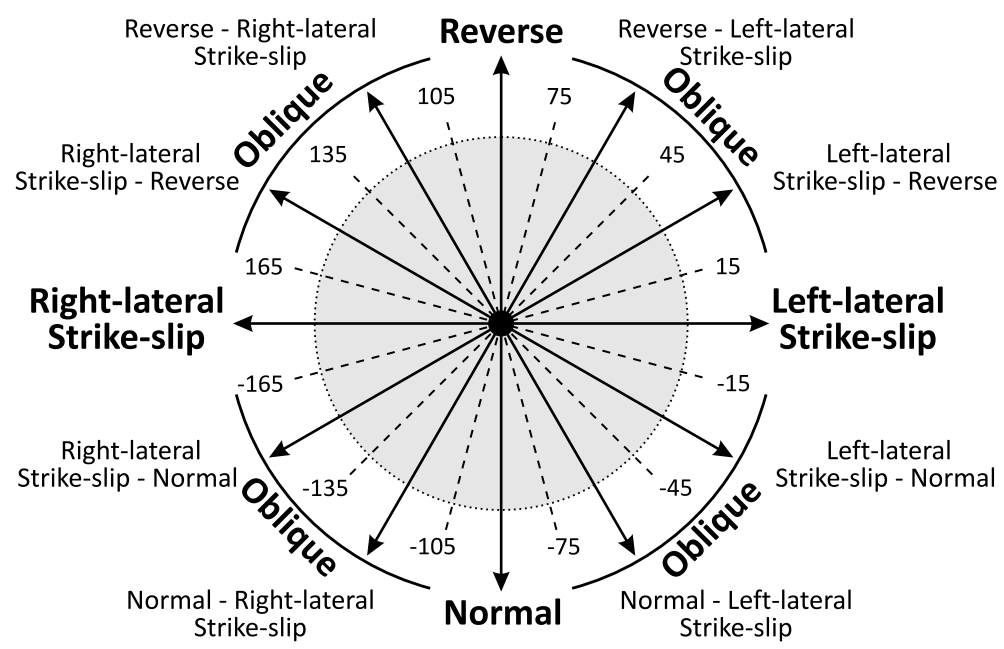

Fig. 8. Diagram of how to distinguish the type of fault from the rake angle.

diagram is used to represent the comparison. As shown in Fig. 9, the choice of the nodal plane in the faulting type diagnosis by using rake is not very significant. 
(a)

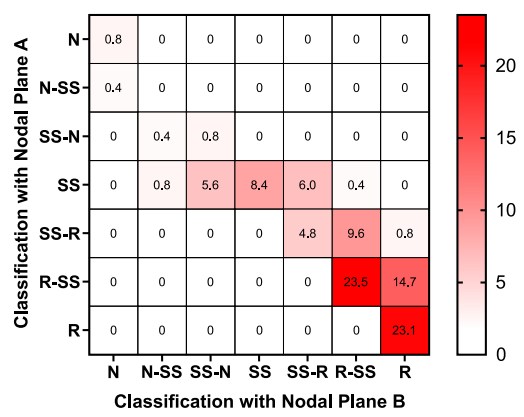

(b)

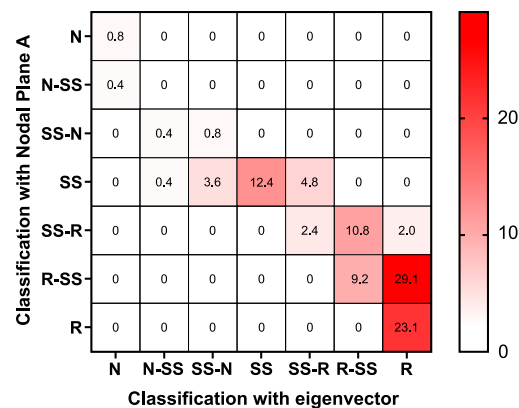

(c)

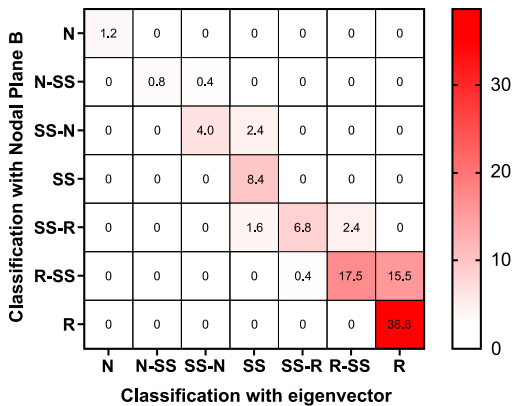

Fig. 9. Heatmaps of relation between: (a) classification with 2 nodal planes, (b) and (c) classification with 1 nodal plane and classification with eigenvector. Numbers show percentages of their frequency.

\section{Conclusion}

In order to understand the seismic properties of the Zagros region better, its focal mechanisms were classified. Due to the large extent of the Zagros, it was divided into three zones for more accurate classification. However, no significant difference was observed in them and it seems that in the classification of Zagros focal mechanisms, it can be considered as an integrated zone. Most of the faults were of inverse and compression type with strikeslip component. Considering that eigenvector analysis of moment tensor has been used in the classification; however, comparison with fault detection by rake angle has shown that both methods can be used as a reliable method in fault detection. 
The interesting point is the discord between the normal condition and the reverse condition, i.e. one plane may show the normal faulting while the other shows the normal faulting with strike-slip component. Also, one may show a reverse faulting and the other plane the reverse faulting with strike-slip component. This feature has also been observed in the diagnosis of faulting by the analysis of eigenvalues.

\section{References}

Álvarez-Gómez J. A., 2018: FMC - A program to manage, classify and plot focal mechanism data. Faculty of Geology, Universidad Complutense de Madrid.

Dziewonski A. M., Chou T.-A., Woodhouse J. H., 1981: Determination of earthquake source parameters from waveform data for studies of global and regional seismicity. J. Geophys. Res. Solid Earth, 86, B4, 2825-2852, doi: 10.1029/JB086iB04p02825.

Ekström G., Nettles M., Dziewoński A. M., 2012: The global CMT project 2004-2010: Centroid-moment tensors for 13,017 earthquakes. Phys. Earth Planet. Inter., 200201, 1-9, doi: 10.1016/j.pepi.2012.04.002.

Gasperini P., Vannucci G., 2003: FPSPACK: a package of FORTRAN subroutines to manage earthquake focal mechanism data. Comput. Geosci., 29, 7, 893-901, doi: 10. 1016/S0098-3004 (03) 00096-7.

Hatzfeld D., Authemayou C., van der Beek P., Bellier O., Lavé J., Oveisi B., Tatar M., Tavakoli F., Walperesdorf A., Yamini-Fard F., 2010: The kinematics of the Zagros Mountains (Iran). In: Leturmy P., Robin C. (Eds.): Tectonic and Stratigraphic Evolution of Zagros and Makran during the Mesozoic-Cenozoic. Geol. Soc., London, Spec. Publ., 330, 19-42, doi: 10.1144/SP330.3.

Kagan Y. Y., 2005: Double-couple earthquake focal mechanism: random rotation and display. Geophys. J. Int., 163, 3, 1065-1072, doi: 10.1111/j.1365-246X.2005.027 $81 . \mathrm{x}$.

Kaverina A. N., Lander A. V., Prozorov A. G., 1996: Global creepex distribution and its relation to earthquake-source geometry and tectonic origin. Geophys. J. Int., 125, 1, 249-265, doi: 10.1111/j.1365-246x.1996.tb06549.x.

Mirzaei N., Gao M., Chen Y. T., 1998: Seismic source regionalization for seismic zoning of Iran: major seismotectonic provinces. Journal of Earthquake Prediction Research, 7, 4, 465-495.

The Global Centroid-Moment-Tensor Project: Global CMT Catalog Search page, accessible at https://www.globalcmt.org/CMTsearch.html. 